\title{
Utilization of Electrospun Polystyrene Membranes as a Preliminary Step for Rapid Diagnosis
}

\author{
Tuğba Isık, Nesrin Horzum,* Ü. Hakan Yıldız, Bo Liedberg, \\ Mustafa M. Demir*
}

Recent advances in clinical practice drive deoxyribonucleic acid (DNA) as an important class of biomarker. Monitoring the change in their concentration suggests the initiation and/or progression of various disorders. However, low quantity of DNA biomarkers in body fluids requires a delicate isolation methodology that provides efficient separation and easy handling. This study describes a newer-generation separation technology relying on electrospun fibers of sub-micrometer diameter of a commodity polymer for DNA biomarkers in simulative serum. Fibrous polystyrene membranes are prepared by electrospinning and they are subjected to post-modification with $\mathrm{Au}$. The composite membranes may provide a convenient environment for the removal of bovine serum albumin (BSA) from BSA and DNA mixtures. The eluent can be used as an efficient tool for detection of DNA biomarkers associated with diagnosis of numerous lifethreatening diseases.

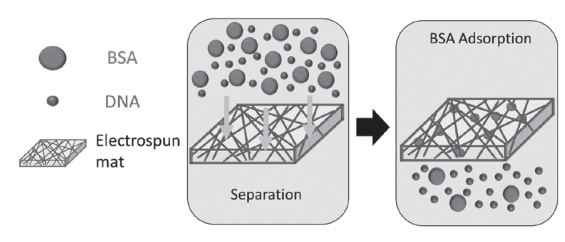

\section{Introduction}

Early detection of any disease remarkably improves the possibilities for successful treatment. Recognition of warning signs and taking precautions against disease

T. Isık, Prof. M. M. Demir

Department of Materials Science and Engineering

Izmir Institute of Technology

35430 Urla, İzmir, Turkey

E-mail: mdemir@iyte.edu.tr

Dr. N. Horzum

Department of Engineering Sciences

Izmir Katip Çelebi University

35620 Çiğli, İzmir, Turkey

E-mail: nesrin.horzum.polat@ikc.edu.tr

Dr. Ü. H. Yildiz

Department of Chemistry

Izmir Institute of Technology

35430 Urla, İmir, Turkey

Prof. B. Liedberg

Center for Biomimetic Sensor Science

School of Materials Science and Engineering

Nanyang Technological University

Singapore progression are two major factors of an early recovery. Recent advances in the use of blood tests for early detection of various types of diseases hold great promise for achieving precise yet cost-effective diagnoses. Monitoring biomarkers in the bloodstream and their concentrations are crucial for early detection of diseases. ${ }^{[1]}$ Deoxyribonucleic acid (DNA) emerges as an important class of biomarkers enabling early detection of both acute medical emergencies and critical progressive diseases. A change in the amount of DNA biomarkers can be measured at any point in time and can be used in detection and progression steps. ${ }^{[2]}$ However, collection/isolation of DNA biomarkers from body fluids is still a challenge since the protein content in blood samples severely interfere. ${ }^{[3-5]}$ Current nucleic acid assays hold promise for the detection of DNA biomarkers; however, many of these novel assays are vulnerable to interfering species. ${ }^{[6,7]}$ Moreover nucleic acid purification processes often require a harsh extraction environment, and the use of certain reagents result in degradation of the molecules. ${ }^{[8]}$ Handling the intrinsic low concentration of DNA biomarkers in blood is challenging and requires novel and innovative separation methodologies techniques is obvious. The utilization of affinity membranes provides selectivity to capture the 
nucleic acids on the membrane surface. ${ }^{[9]}$ Fibrous affinity membranes prepared by the electrospinning process have been attracting increasing attention in the bioseparation field because of their structural advantages that stem from their enhanced surface area, high porosity, and ease of surface functionalization. The key parameter in such systems is the fiber morphology (i.e., thickness, shape, and porosity), which can be controlled via solution, instrumental, and environmental parameters. ${ }^{[10,11]}$ The resulting fibers have mechanical integrity and can resist mechanical forces in various applications. ${ }^{[12]}$ In addition, the surface of the electrospun fibers can be functionalized via pre- or post-treatments because of the fibers' interfiber spacing in mat-like structures. ${ }^{[13,14]}$ The use of electrospun membranes in the separation of biomolecules has been recently recognized. Ramakrishna and coworkers used nylon fibers decorated with zinc-doped hydroxyapatite nanoparticles (NPs) to adsorb bovine serum albumin (BSA). In addition, the same authors used cellulose acetate membranes with immobilized Cibacron Blue for the adsorption of BSA and bilirubin. ${ }^{[15-17]}$ In contrast, the use of metal ions changes the surface charge of the membranes and enhances the adsorption capacity of specific molecules, and immobilization of various molecules can be used to tune the binding affinity. Nitrate-modified cellulose diacetate ${ }^{[18]}$ and polyacrylonitrile $(\mathrm{PAN})^{[19]}$ membranes were prepared for the removal of BSA from aqueous systems. Fort et al. demonstrated the use of carbohydrate-decorated polycaprolactone electrospun fibers for the adsorption of specific lectins, which are carbohydrate-binding proteins. ${ }^{[20]}$ Moreover, BSA and lysozyme separation was investigated on cellulose acetate nanofibers functionalized with diethylaminoethyl or carboxylate groups. ${ }^{[21]}$ The separation of lysozyme from chicken egg white was studied by Chiu and his coworkers, who used a combination of electrospinning and alkaline hydrolysis processes to prepare PAN nanofibrous membranes. ${ }^{[2]}$ Molecularly imprinted electrospun membranes have also attracted considerable attention because of their specific recognition sites. The fibrous membranes with multimodal pore structures were developed for the adsorption of template BSA and hemoglobin molecules. ${ }^{\text {[23] }}$ Protein adsorption has been also used in cell attachment applications. The adsorption of fetal serum albumin on electrospun poly(D,L-lactide) nanofibrous membranes was examined by Leong and co-workers. ${ }^{[24]}$ However, the separation of nucleic acids from proteins has not been a focal point of previous studies.

In this study, we use a convenient approach to develop an affinity membrane for the separation of DNA biomarkers from BSA. The strategy is based on the retrieval of DNA by adsorption of BSA from a BSA + DNA solution mixture using column experiments. Given the intrinsic hydrophobicity and the inter- and intraporous structure of polystyrene (PS), ${ }^{[25]}$ the use of its electrospun membranes may be an alternative filter material for bioseparation processes. PS, as a common commodity vinyl polymer, was electrospun from solution. The separation efficiency of the electrospun membranes was examined using a model mixture of BSA and single-stranded DNA (ss-DNA) in simulative serum. A single-stranded DNA sequence with 22 nitrogenous bases was selected as a representative DNA biomarker.

\section{Experimental Section}

\subsection{Materials}

PS $\left(M_{\mathrm{w}} \approx 350 \mathrm{~kg} \mathrm{~mol}^{-1}\right.$, Aldrich), BSA ( $\geq 98 \%$, Sigma-Aldrich), and ss-DNA oligonucleotide 5'-TAG-CTT-ATC-AGA-CTG-ATG-TTGA-3' (Sigma-Aldrich) were used without any further purification. Phosphate-buffered saline (PBS, Sigma), sodium pyromellitate buffer solution (HPCE, $20 \times 10^{-3} \mathrm{M}$, pH 9.0, Fluka), tris-EDTA (100× for molecular biology, Sigma), sodium acetate (pH 5.12, Fluka) buffer solution, hydrochloric acid ( $\mathrm{HCl}, 37 \%$, Sigma-Aldrich), and sodium hydroxide ( $\mathrm{NaOH}, \geq 98 \%$, Sigma Aldrich) were used for $\mathrm{pH}$ adjustment. Gold(III) chloride hydrate $\left(\mathrm{HAuCl}_{4}, 99.99 \%\right.$, Aldrich) and trisodium citrate dihydrate $\left(\mathrm{C}_{6} \mathrm{H}_{5} \mathrm{Na}_{3} \mathrm{O}_{7} \cdot 2 \mathrm{H}_{2} \mathrm{O},>99 \%\right.$, Sigma-Aldrich) were used for surface modification experiments. $N, N$-Dimethylformamide (DMF, 99\%, Carlo Erba), ethanol ( $\geq 99.5 \%$, Sigma-Aldrich), and water (molecular biology reagent, Sigma) were used as solvents. Coomassie blue stain was supplied by Sigma. Magnesium chloride hexahydrate $\left(\mathrm{MgCl}_{2} \cdot 6 \mathrm{H}_{2} \mathrm{O}, \mathrm{Merck}\right)$, calcium chloride $\left(\mathrm{CaCl}_{2}\right.$, Aldrich), D-(+)-glucose $(\geq 99.5 \%$, Sigma), potassium chloride ( $\mathrm{KCl}$, Merck), urea (ACS reagent, 99.0\%$100.5 \%$, Sigma-Aldrich), and sodium chloride ( $\mathrm{NaCl}$, Merck) were used without further purification.

\subsection{Fabrication of Electrospun Polystyrene Membranes}

PS was dissolved in DMF at different concentrations (15, 25, and $30 \mathrm{wt} \%$ ) and stirred for $24 \mathrm{~h}$ until homogeneous solutions were achieved. The polymer solutions were transferred to $20 \mathrm{~mL}$ plastic syringes with a stainless steel needle (18 gauges), and the needle was connected horizontally to a high-voltage power supply under $15 \mathrm{kV}$ potential (Gamma High Voltage Research Ormond Beach, FL, US). A microsyringe pump (LION WZ-50C6) was used to fix the flow rate at $5 \mathrm{~mL} \mathrm{~h}^{-1}$, and the tip-to-collector distance was $15 \mathrm{~cm}$. Fluffy PS fibers were obtained on the grounded aluminum plate with $45 \mathrm{RH} \%$ at $20^{\circ} \mathrm{C}$. For the surface modification, PS electrospun membranes were immersed in $\mathrm{HAuCl}_{4}$ solution $\left(3.25 \times 10^{-3} \mathrm{M}, 40 \mathrm{~mL} \mathrm{~g}^{-1}\right.$ fiber) at room temperature; the immobilization process was conducted for $48 \mathrm{~h}$ on an orbital shaker at $240 \mathrm{rpm}$ (IKA-WERKE Yellow Line, Germany). The reduction of gold cations on the fiber surface was subsequently induced by adding trisodium citrate solution $\left(8.2 \times 10^{-3} \mathrm{M}, 40 \mathrm{~mL} \mathrm{~g}^{-1}\right.$ fiber $)$, and the solutions were shaken for an additional $4 \mathrm{~h}$. The membranes were then removed from the solutions and dried under room temperature.

The morphology of the electrospun membranes was observed using a scanning electron microscope (SEM) (FEI Ouanta 250 FEG, Oregon, USA). Elemental analysis was conducted 
using energy-dispersive X-ray spectroscopy (EDS), and fiber diameter distributions were estimated statistically from SEM micrographs using ImageJ $1.50 \mathrm{~b}$ software. ${ }^{[26]}$ The surface area of the electrospun membranes was measured using the BrunauerEmmett-Teller (BET) gas adsorption method (Micromeritics Gemini V, GA, USA). The thermal properties of the PS/Au membranes were analyzed using a Perkin-Elmer Diamond TG/DTA.

\subsection{Adsorption Study}

As-prepared membranes were used as an adsorbent for the removal of BSA molecules from a model solution. The electrospun membranes were placed into the homemade syringe column with an inner diameter of $15 \mathrm{~mm}$. PBS was dissolved in $200 \mathrm{~mL}$ of deionized water, which yielded $0.01 \mathrm{M}$ phosphate buffer. Tris-EDTA buffer $(100 \times)$ was diluted to $1 \times$ in water to obtain a pH 8 buffer solution, and sodium pyromellitate buffer solution was diluted to $1 \times 10^{-3} \mathrm{M}$ with water to obtain a $\mathrm{pH}$ 9 buffer. Sodium acetate buffer solution was used for $\mathrm{pH}$ 5.12. For the adjustment of $\mathrm{pH}, \mathrm{HCl}$ or $\mathrm{NaOH}$ was used. DNA was dissolved to a concentration of $100 \times 10^{-3} \mathrm{M}$ in PBS buffer. To avoid freezeand-thaw cycles, the $100 \times 10^{-6} \mathrm{M}$ DNA was diluted to $1 \times 10^{-6} \mathrm{M}$ fractions in 1.5-mL volumes, and molten samples were not frozen again. The BSA solutions were prepared in PBS buffer. The mixture of BSA and DNA solutions was prepared in equivolume (10 and $1 \times 10^{-6} \mathrm{M}$, respectively). The fibrous membrane-filled syringe column was wet with $1 \mathrm{~mL}$ of PBS buffer before the adsorption study. The analyte solutions were then passed through the electrospun membranes, and the eluted solutions were analyzed using a UV-vis spectrometer (SHIMADZU, UV 2450, Japan). To investigate the effect of membrane amount, columns were prepared with 5-, 10-, 20-, 40-, and 80-mg membranes, and the same process was applied for BSA adsorption. Coomassie blue solution (prepared in 50\% methanol-10\% acetic acid-40\% water mixture) was used for the visualization of BSA after the filtration process. To this end, the electrospun membranes after BSA adsorption were collected from the column and treated with Coomassie dye for $30 \mathrm{~min}$ at $150 \mathrm{rpm}$ in an orbital shaker. The dye-treated membranes were then immersed into the destaining solution to remove free dye molecules. The applicability of the membrane filters was investigated using a simulative serum solution prepared using $4.5 \times 10^{-3} \mathrm{M} \mathrm{KCl}, 5 \times 10^{-3} \mathrm{M}$ $\mathrm{CaCl}_{2}, 1.6 \times 10^{-3} \mathrm{M} \mathrm{MgCl}_{2}, 4.7 \times 10^{-3} \mathrm{M} \mathrm{D}-(+)$-glucose, $2.5 \times 10^{-3} \mathrm{M}$ urea, $0.1 \% \mathrm{BSA}$, and $145 \times 10^{-3} \mathrm{M} \mathrm{NaCl}^{[27]}$ The separation efficiency of the membranes was investigated using the aforementioned procedure. After adsorption, the morphology of the membranes' fibers was examined using microscopy.

\section{Results and Discussion}

\subsection{Morphology of Electrospun Fibrous Membranes}

PS membranes consisting of sub-micrometer-diameter nonwoven fibers were prepared by electrospinning from DMF solutions. Figure 1a shows a representative overview SEM micrograph of the membrane prepared from $15 \mathrm{wt} \%$
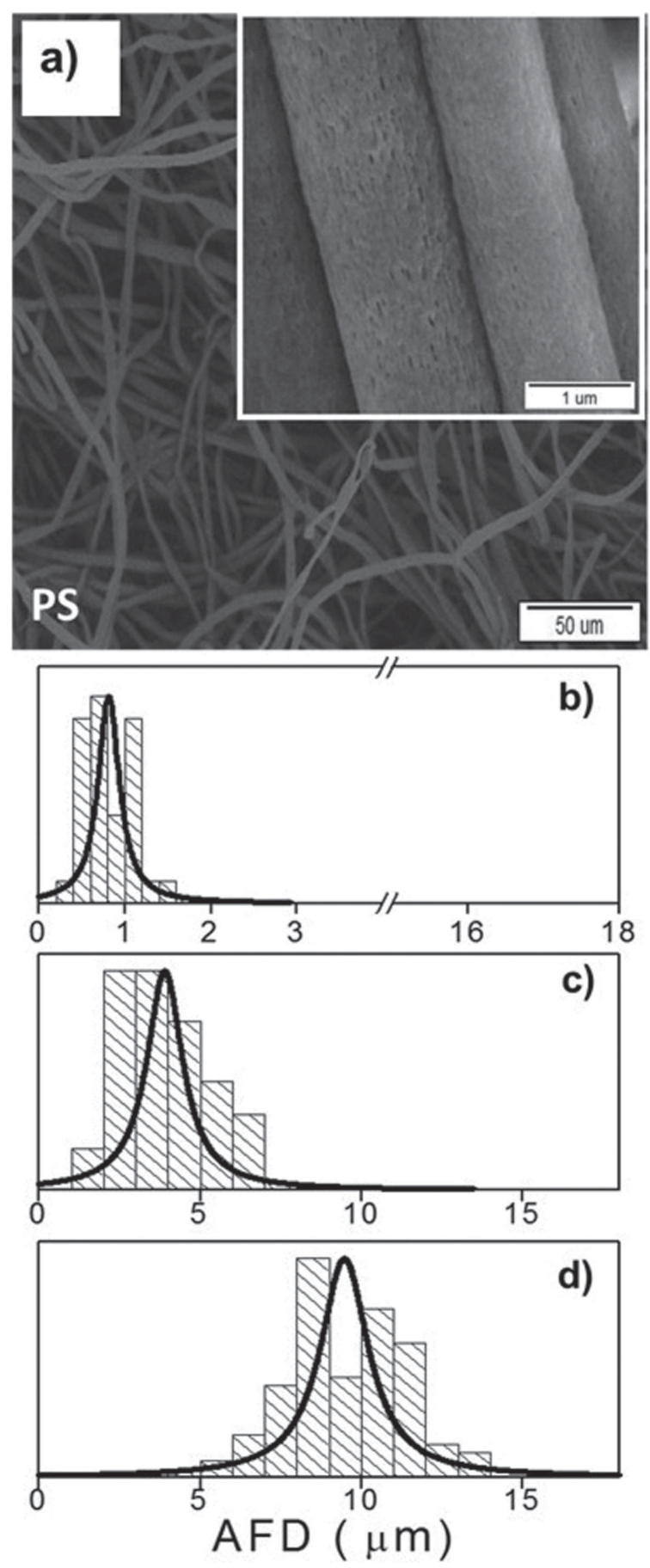

Figure 1. a) Representative SEM micrograph of PS membrane prepared from electrospinning of DMF solution at $15 \mathrm{wt} \%$ concentration, and fiber diameter distributions of PS fibers electrospun from b) $15 \mathrm{wt} \%$, c) $25 \mathrm{wt} \%$, and d) $30 \mathrm{wt} \%$ PS/DMF solutions.

PS solution. The inset presents a higher-magnification image showing the surface feature of the constituent fibers. PS fibers exhibit a porous and rough surface morphology most probably due to phase separation between DMF and moisture in air associated with rapid solvent evaporation from the spinning jet. ${ }^{[25,28,29]}$

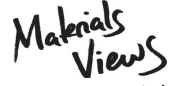

www.MaterialsViews.com 
Table 1. BET results for liquid nitrogen adsorption on electrospun PS nanofibers.

\begin{tabular}{lcccc}
\hline AFD & BET surface area & Langmuir surface area & Single point area Pore size \\
{$[\mu \mathrm{m}]$} & {$\left[\mathrm{m}^{\mathbf{2}} \mathbf{g}^{-1}\right]$} & {$\left[\mathrm{m}^{2} \cdot \mathrm{g}^{-\mathbf{1}}\right]$} & 47.4 & 400.4 \\
\hline 0.8 & 51.9 & 74.1 & 36.1 & 335.3 \\
3.9 & 39.3 & 55.9 & 33.5 & 164.9 \\
9.5 & 36.8 & 52.7 & &
\end{tabular}

of the electrospun fibers. A low space is formed during the deposition of thin electrospun fibers, which may also contribute to the removal of BSA. ${ }^{[33-37]}$ As a result, thin fibers are preferred for the BSA adsorption because they exhibit both a large surface area and small inter-fibrillar spacing. On the other hand chemical affinity between PS and
Figure $1 b-d$ represents the average fiber diameter (AFD) distributions of the PS fibers. We controlled the AFD between $0.8 \pm 0.3$ and $9.5 \pm 2.9 \mu \mathrm{m}$ by simply changing the polymer concentration. Increasing the PS concentration results in entanglements of the polymer chains and increases the viscosity of the solution. ${ }^{\left[{ }^{[0]}\right.}$ As the viscosity increases, the solution becomes sufficiently strong to discourage the bending instability of the jet. Stretching of the jet because of high electrical potential in the spinning process is reduced; ${ }^{[31]}$ as a result, the mean of the fiber diameter distribution shifts to larger diameters. In agreement with the literature results, ${ }^{[32]}$ the diameter of PS fibers increases as the third power of the solution concentration (Figure S1, Supporting Information). The BET method was used to determine the surface area characteristics of the PS fiber assemblies (Figure S2, Supporting Information). Table 1 presents the nitrogen adsorption results for the PS fibers prepared at different concentrations. The surface area of the PS fibers was ranged from 51.9 to $36.8 \mathrm{~m}^{2} \mathrm{~g}^{-1}$ showing a systematic decrease as AFD increases.

\subsection{BSA Adsorption}

The fibrous PS membranes were first utilized for the adsorption of BSA. The adsorption of BSA molecules was performed in a column with a fixed amount of the PS membrane. To determine the concentration of BSA, we constructed a calibration graph of the absorbance of a series of BSA solutions of known concentrations (Figure S3, Supporting Information). Figure 2a shows the absorption spectra of the BSA solution before and after the sorption process. The spectrum of BSA shows an absorption signal at $280 \mathrm{~nm}$. The intensity of the signal was found to decrease after sorption. The effect of fiber diameter on the BSA adsorption was investigated. Figure $2 \mathrm{~b}$ presents the adsorbed amount of BSA per gram of PS membranes with different AFDs. A close relationship between the AFD and adsorption performance was observed. The amount of adsorption increased as the fiber diameter decreased. Electrospun membranes consisting of thin fibers exhibit high BSA adsorption, most likely as a consequence of the fibers' large effective surface area. Fiber diameter also determines the inter-fibrillar space (sieve size) in the electrospun mat during the deposition
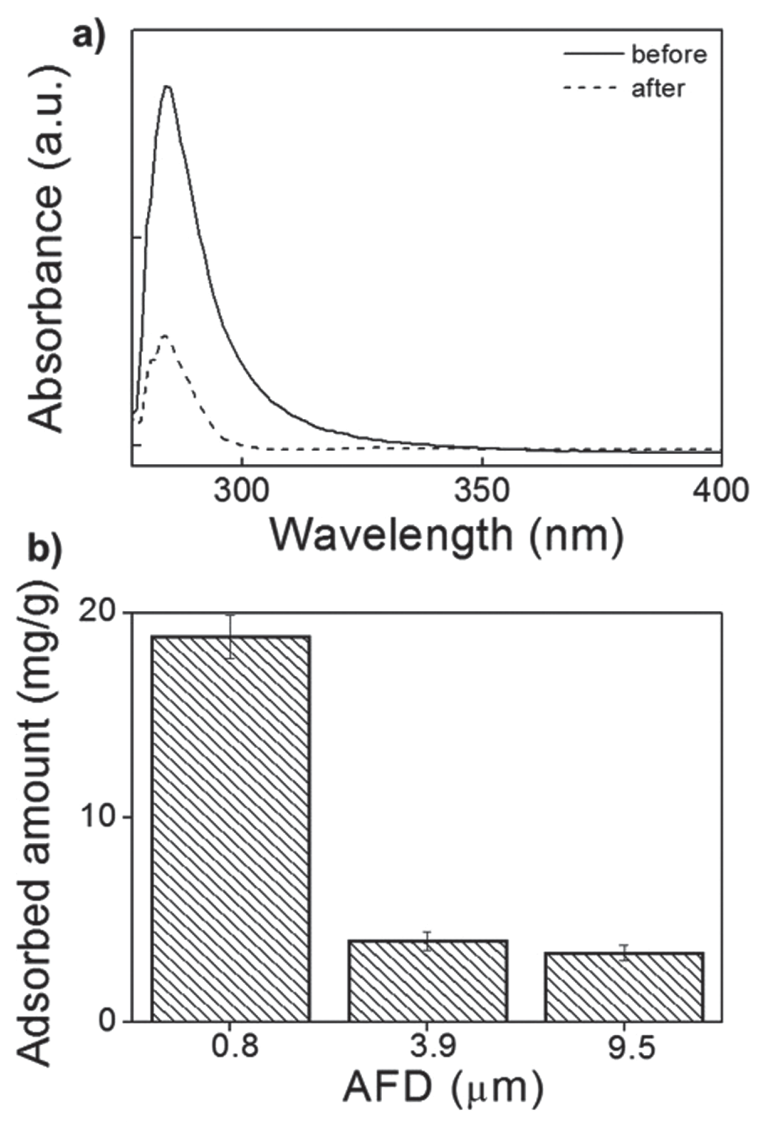

c)

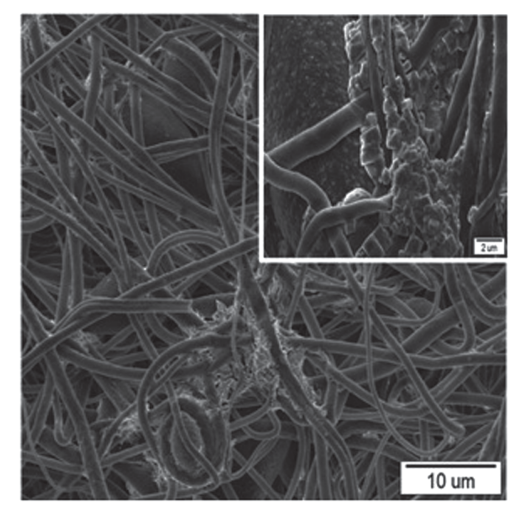

Figure 2. a) UV-vis spectra of initial BSA and final eluent solutions filtrated through PS ( 15 wt\%) membranes b) the effect of AFD on BSA adsorption for the PS membranes, and c) SEM micrograph of PS (15 wt\%) membrane after BSA adsorption. (The concentration of BSA is $10 \times 10^{-6} \mathrm{M}$.) 


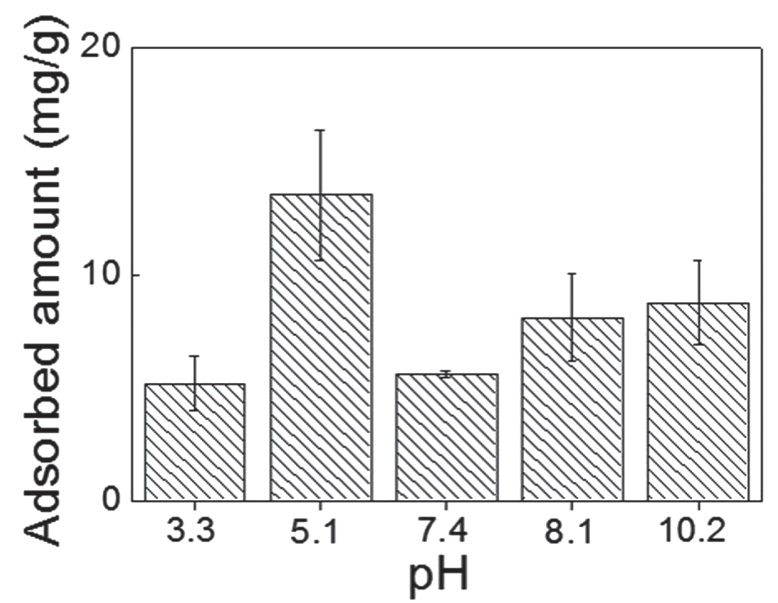

Figure 3. The effect of $\mathrm{pH}$ on the adsorption of BSA on the electrospun PS membranes (15 wt\%).

BSA plays an active role in the adsorption process. ${ }^{[38-40]}$ BSA is composed of $\approx 600$ amino acid residues, and some of these amino acids, such as phenylalanine, tyrosine, and tryptophan, have aromatic structures. When hydrophobic groups of proteins and the fiber surface come in close proximity, they can interact with a pendant benzene ring of PS via $\pi-\pi$ interaction, resulting in the adsorption of BSA molecules/clusters.

Figure 2c shows the electrospun PS fiber membrane after the BSA adsorption process. The morphology of the fibers remains unchanged, and the electrospun membrane preserves its mechanical integrity. Compared to the neat PS membranes shown in Figure 1, a new phase appears among the electrospun fibers after adsorption. This phase is attributed to the presence of BSA or clusters sieved by the electrospun membrane system. EDX analysis was performed on this new phase, which revealed the presence of nitrogen, which is not present in the molecular structure of PS. This presence of nitrogen atoms in the clusters suggests that this new phase in the PS membrane is rich in BSA molecules.

The $\mathrm{pH}$ of the dispersing medium strongly influences the conformation of BSA and, in turn, its adsorption characteristics by creating an electrostatic double-layer around the molecule. Figure 3 demonstrates the experimental adsorption capacity of BSA molecules at different $\mathrm{pH}$ levels. The capacity reaches a maximum at $\mathrm{pH}$ $=5.1$, which is similar to the isoelectric point (IEP) of BSA (4.8). The quantity of negatively and positively charged groups near the IEP is approximately same and there is no net charge on the protein. Thus, the size of the molecule decreases due to the mutual attraction of differently charged groups. BSA takes globular conformation with normal $(\mathrm{N})$ isomeric form and $67 \%$ of the structure is $\alpha$-helical. ${ }^{[41]}$ When its net charge is small, the adsorbed amount on the electrospun membranes showed a

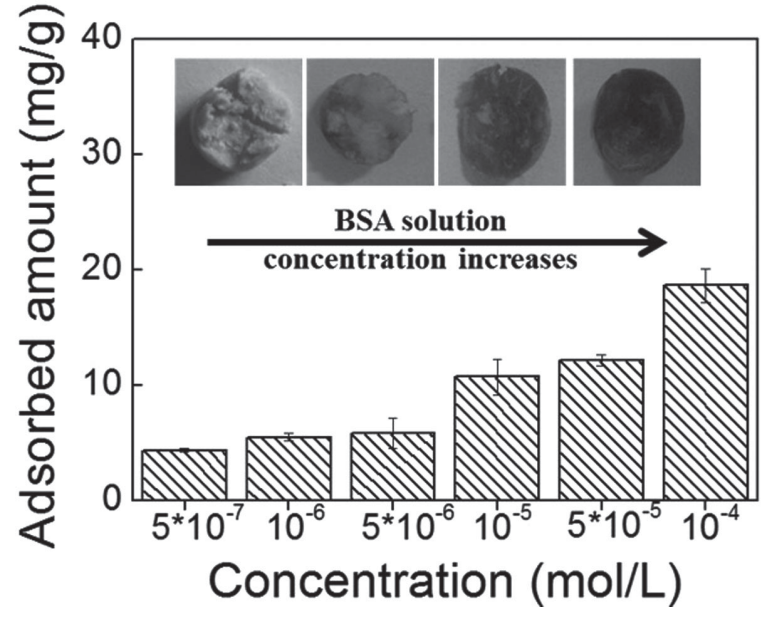

Figure 4. Effect of initial concentration on the adsorbed BSA amount. The inset is the photographic images of PS membranes treated with a Coomassie blue staining after BSA adsorption.

remarkable increase at $\mathrm{pH}=5.1$ due to likelihood of neutral PS surface. ${ }^{[42]}$

Figure 4 represents the effect of the initial concentration of BSA on the adsorption capacity of PS membranes. The increase in BSA concentration results in increased adsorption. The presence of BSA on the fibrous membranes was observed by the naked eye using Coomassie blue stain. The change in the intensity of the dye also confirmed the high capacity of BSA adsorption.

\subsection{DNA Adsorption}

UV-vis spectroscopy was used to determine the DNA concentration according to the Beer-Lambert law. DNA molecules show an absorption signal at $260 \mathrm{~nm}$ (Figure S4, Supporting Information). PS membranes containing electrospun fibers with different thicknesses were investigated in a manner similar to the BSA adsorption experiments. In sharp contrast to BSA, the adsorption of DNA increases with the fiber diameter. Surface curvature has been demonstrated to reduce the sorption of DNA molecules so that they prefer to adsorb onto flat surfaces. ${ }^{[43-45]}$ Consistent with this hypothesis, we observed that as the curvature increases (thin fibers), the amount of DNA adsorption was lower because of intermolecular repulsions that originated from the negative charge of the phosphodiester backbone. Figure 5 shows that the DNA adsorption increased threefold as the AFD was increased from 0.8 to $9.5 \mu \mathrm{m}$.

\subsection{Adsorption of Model Mixture: BSA and DNA}

Figure 6 demonstrates the significant effect of fiber diameter on the adsorption of BSA from BSA and DNA mixtures. The sorption behavior of the both the bioanalytes in

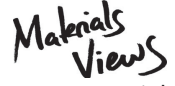

www.MaterialsViews.com 


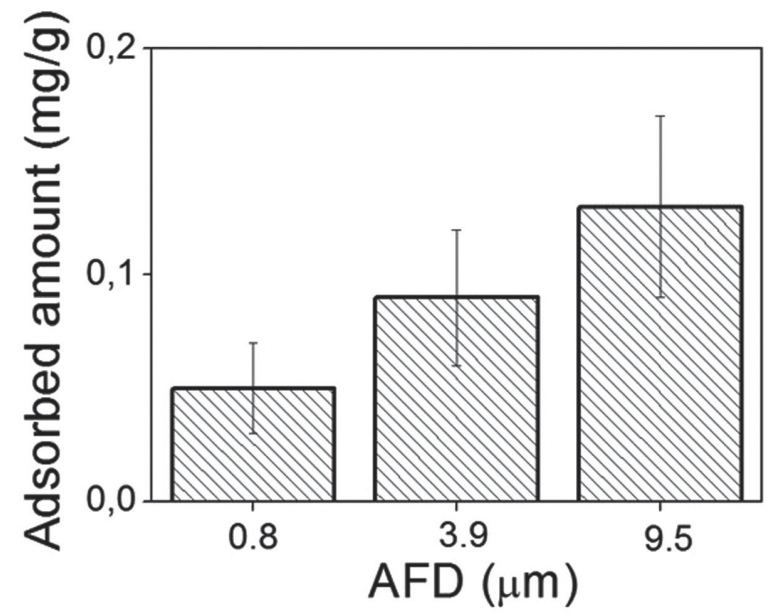

Figure 5. Effect of PS fiber diameter on the adsorbed DNA amount. (The concentration of DNA is $1 \times 10^{-6} \mathrm{M}$.)

the mixture is similar to that of each analyte alone (either BSA or DNA), i.e., reducing AFD increases the BSA sorption and decreases DNA sorption, which is in good agreement with the observations shown in Figures $2 \mathrm{~b}$ and 5 . However, the sorption level of both bioanalytes in the mixture is lower compared to their sorption level on the PS membrane when used alone (Table 2).

For instance, whereas the sorption of BSA alone was $18.8 \mathrm{mg} \mathrm{g}^{-1}$, it was reduced to $7.5 \mathrm{mg} \mathrm{g}^{-1}$ when the mixture of BSA and DNA was used. This reduced performance can be explained by the competitive sorption of the both analytes. Consistent with adsorption results for BSA and DNA alone, thin fibers efficiently catch BSA clusters and are reluctant to adsorb DNA. The performance of the

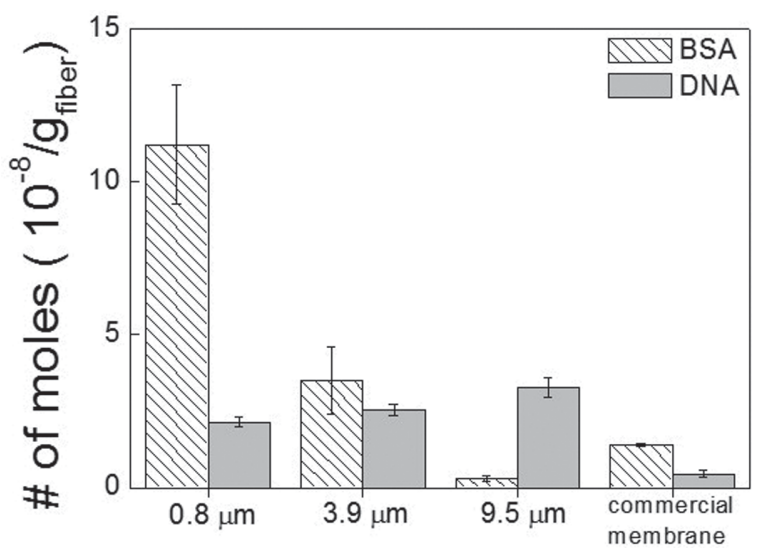

Figure 6. The comparison of BSA/DNA separation efficiency by PS membranes having different AFD and a $0.45 \mu \mathrm{m}$ cellulose acetate membrane. (The amount of membranes was fixed to $5 \mathrm{mg}$ for each trial.) When the sorption capacity is used as a unit for sorption performance, the values are getting close to each other. So that $Y$-axis of the plot is given in number of moles of analytes adsorbed by per $g$ of the fibers for the ease of comparison.
PS membranes was compared with that of commercial cellulose acetate membranes. The results show that the PS membranes display higher separation efficiencies compared to that of the commercial membrane. Consequently, a membrane consisting of thin electrospun PS fibers is promising for the separation of BSA molecules in the presence of DNA.

We monitored the BSA/DNA ratio to qualitatively and rapidly compare the membrane performance. Note that a low ratio is desired because the concentration of BSA needs to be reduced faster than that of DNA. Figure 7 shows the effect of the membrane amount on the BSA/DNA ratio in the material adsorbed onto the PS membrane and in the eluted solutions. When a small amount of membrane was used ( $5 \mathrm{mg}$ ), the ratio (BSA/ DNA: 19) was approximately the same as the initial ratio (BSA/DNA: 21) of the fresh solution before adsorption. Increasing the amount of membrane to $80 \mathrm{mg}$ resulted in a remarkable decrease in the BSA/DNA ratio in the eluted solution (BSA/DNA: 8). This result suggests that the concentration of BSA decreases rapidly, whereas the amount of DNA reduces slowly. Thus, the ratio decreases in favor of increasing DNA concentration.

An alternative syringe column system was examined to gain further insight into the performance of the electrospun membranes. In this system, the BSA and DNA mixture was passed through the syringe columns consecutively. The eluent was passed through a new membrane system numerous times, one after the other. The membrane amount was $5 \mathrm{mg}$ for each measurement. UV-vis spectra of the eluted solutions were successively recorded. Figure 8 presents the separation results of the serial column system. The BSA/DNA ratio systematically decreases for the eluted solutions from 21 to 12 after 12 cycles. A greater number of cycles was expected to result in increased concentration of DNA compared to that of BSA; however, the membrane deteriorated and the fibers disintegrated. Consequently, a one-step process using a large amount of the membranes provided better efficiency than the consecutive filtration for the isolation of DNA.

\subsection{Surface Modification of the PS Membranes}

$\mathrm{Au}$ nanoparticles ( $\mathrm{Au}$ NPs) have been recognized as convenient materials for biomedical applications because of their excellent biocompatibility, low toxicity, tunable colloidal stability, and resistance to bacterial infection. ${ }^{[46]}$ In order to improve the separation efficiency of the PS membranes, we decorated the individual fibers of the membrane with Au NPs. An electrospun membrane of $80 \mathrm{mg}$ was used as a substrate for surface modification. Figure 9a,b presents PS membranes modified by Au NPs. Bright spots on the surface of electrospun fibers refer to $\mathrm{Au}$ 
Table 2. Adsorbed amount of analytes on PS membranes.

\begin{tabular}{lcccc}
\hline $\begin{array}{l}\text { AFD } \\
{[\mu \mathrm{m}]}\end{array}$ & $\begin{array}{c}\text { Single BSA } \\
{\left[\mathrm{mg} \mathrm{g}^{-1}\right]}\end{array}$ & $\begin{array}{c}\text { Single DNA } \\
{\left[\mathrm{mg} \mathrm{g}^{-1}\right]}\end{array}$ & $\begin{array}{c}\text { BSA in mix } \\
{\left[\mathrm{mg} \mathrm{g}^{-1}\right]}\end{array}$ & $\begin{array}{c}\text { DNA in mix } \\
{\left[\mathrm{mg} \mathrm{g}^{-1}\right]}\end{array}$ \\
\hline 0.8 & 18.82 & 0.046 & 7.46 & 0.015 \\
3.9 & 3.97 & 0.093 & 2.32 & 0.086 \\
9.5 & 3.39 & 0.130 & 0.21 & 0.230
\end{tabular}

\subsection{Discussion}

Protein adsorption is complex and mainly driven by entropic parameters. The conformational change is the primary driving force for the adsorption process. This change arises from the sidechain orientations and alteration of the main torsional angles in polypeptides. ${ }^{[51]}$

domains (Figure 9c). Because the membrane was subjected to post-surface modification, the particles were selectively nucleated on the surface of the fibers. The Au content was determined by thermogravimetric analysis and was observed to be $3 \%$ for PS/Au composite fibers (Figure S5, Supporting Information). The mean diameter of the particle domains was $50 \mathrm{~nm}$. (Figure 9d) Binding of BSA molecules to an Au surface can be accomplished by taking advantage of extremely stable thiol-Au bonds. ${ }^{[47-50]}$ Thiol groups on a serum albumin sequence increase the binding efficiency to the $\mathrm{Au}$ surfaces. These $\mathrm{Au}$ NPs enhance the BSA adsorption performance of the membrane and the decrease the BSA/DNA ratio in the eluted solution. Whereas the ratio of BSA/DNA was decreased from 21 to 8 for the best performance obtained by neat electrospun PS membranes, this ratio was reduced to 5 upon Au NPs' decoration of PS fibers.

The results indicated that an Au-modified PS membrane prepared with $80 \mathrm{mg}$ of electrospun fibers exhibited the best performance, at least under the experimental conditions employed in this study. This membrane was applied to both the model system and the simulative serum. The Au-modified PS membranes exhibited high separation efficiency in the model system, whereas this efficiency decreased in the simulative serum medium may be because of the presence of numerous competitive species (Figure S6, Supporting Information).

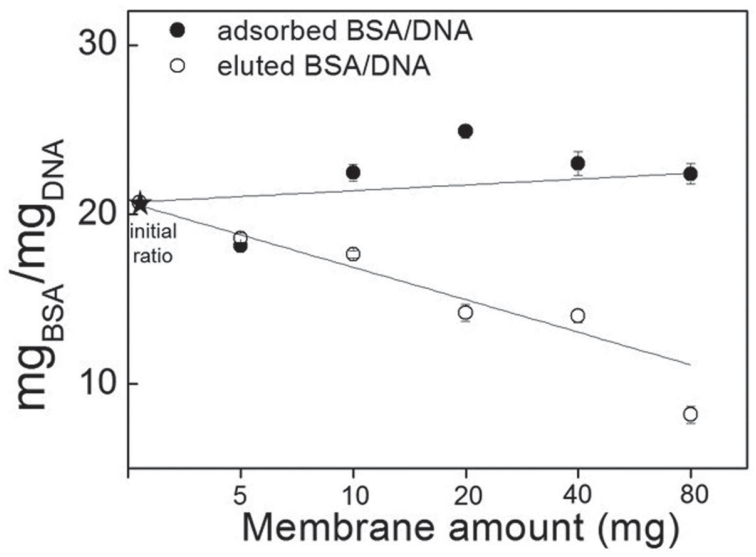

Figure 7. The ratio of the adsorbed BSA to eluted DNA using different weights of PS membranes in syringe columns.
BSA is a globular protein with a highly ordered structure. During the adsorption, protein molecules form various contacts with the surface and the structure may break down. The disruption of the structure leads to a change in the secondary structure and having less rigid structure with an increase in conformational entropy. ${ }^{[52]}$ In sharp contrast to the adsorption of synthetic macromolecules, the adsorption of biomolecules onto a surface increases the entropy of the system. In addition, the large entropy gain results in free hydrophobic groups, and this change causes the release of the water molecules initially held by the biomacromolecules. This partial dehydration develops the balance between hydrophobic and hydrophilic interaction of BSA and the fiber surface. While a fraction of molecules is attached to PS surface, another part form loops and tails interacting with surrounding water molecules. This interaction shows more entropic freedom than rigid hydrated protein structure. Hydrophobic contacts develops enthalpic interactions as well. However, the increase of enthalpy due to the formation of constraints with fiber surface is sufficiently compensated by the two entropy contributions (dehydration and structural change).

In addition to PS, another commodity vinyl polymer, poly (methyl methacrylate) (PMMA), was also tested using this strategy. However, the performance of PMMA was observed to be much lower than that of PS (Figure S7, Supporting Information). A possible explanation for this result is the specific interaction between PMMA and DNA. PMMA has polar carbonyl groups that can interact

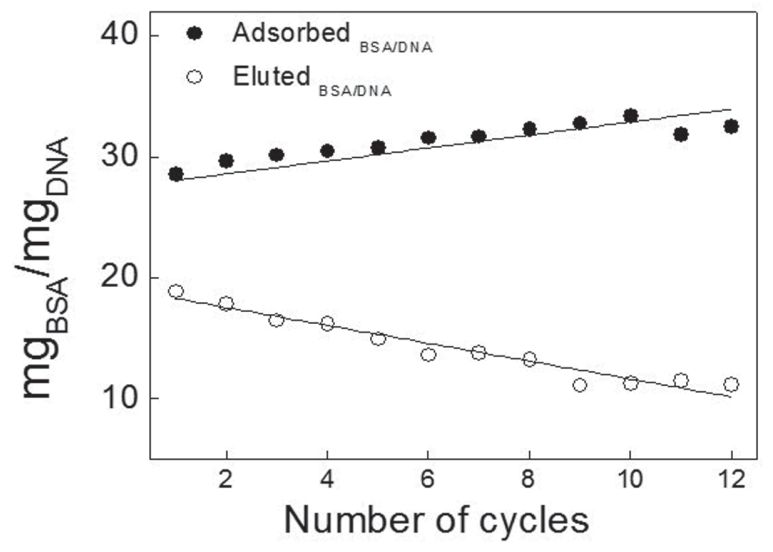

Figure 8. The BSA/DNA ratio as a function of cycle number.

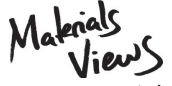

www.MaterialsViews.com 


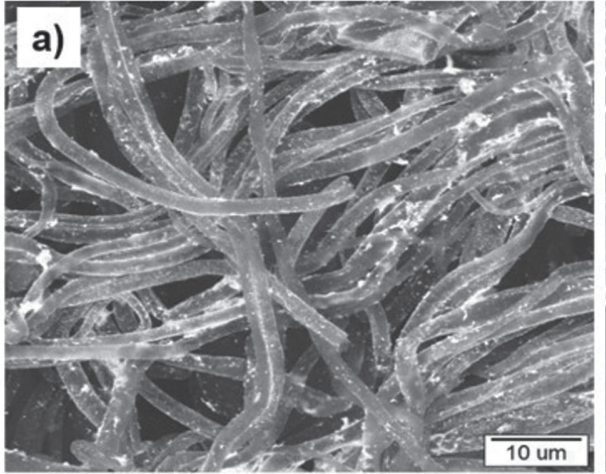

c)

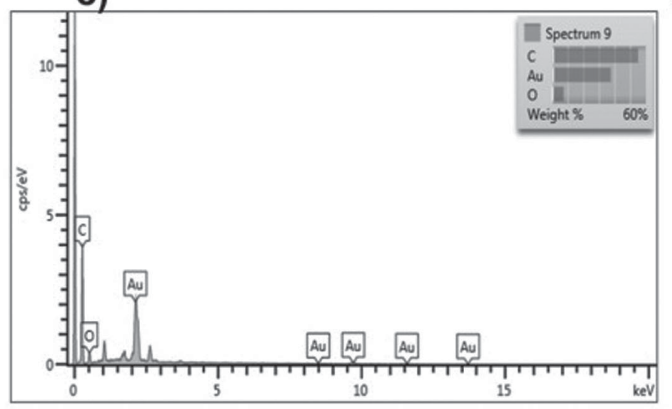

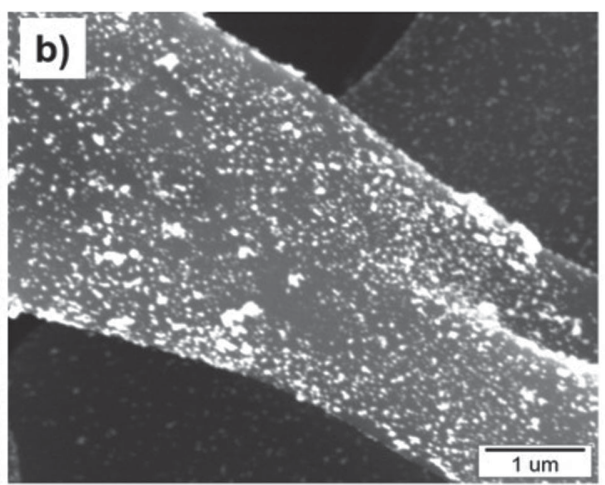

d)

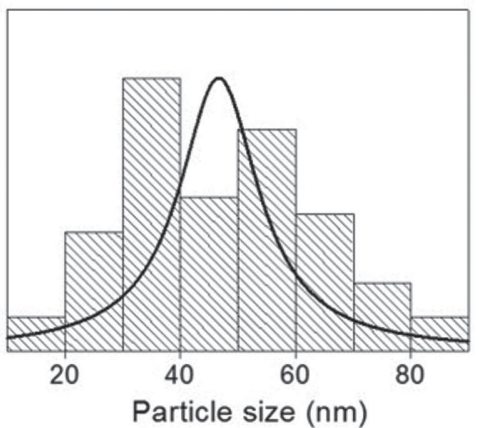

Figure 9. a,b) SEM micrographs of Au modified PS membranes with different magnifications, c) EDS spectrum of membranes and d) particle size of Au NPs on the fibers.

with DNA via H-bonding. Thus, both BSA and DNA were adsorbed by the PMMA membrane, and the BSA/ DNA ratio remained almost unchanged. Because of its hydrophobic nature, PS exhibited better performance in removing BSA from the BSA and DNA mixture.

Adsorption is a surface phenomenon, which means that it depends on equilibrium. In order to better understand the adsorption mechanism, many previous studies have focused on isotherms of analytes. Various isotherm models have been developed. Along with the Langmuir and Langmuir-driven isotherms, the Temkin and Freundlich adsorption isotherms are the most commonly used models for protein-adsorption batch experiments. Because of the limited residence time for the interaction between the sorbent and the solute during dynamic column adsorption, we investigated the saturation point of the membranes using breakthrough curves. The nitrogen adsorption process was used to analyze a representative electrospun membrane after 40 adsorption cycles. After this rigorous adsorption experiment, no remarkable change was observed, except for the presence of a small number of fiber ruptures (Figure S8, Supporting Information). The adsorption capacity does not reach a plateau level after numerous consecutive adsorption experiments. Thus, none of the proposed adsorption models could be applied.

\section{Conclusions}

In this study, we investigated a new generation separation membrane made up of electrospun fibers functionalized with surface-active $\mathrm{Au}$ interface compatible with physiological conditions. The prepared fibrous PS membranes were used for the selective separation of DNA from both model and simulative serum. Surface morphology (porosity, AFD, and curvature of the fiber surface), membrane amount in the syringe column, initial concentration of the analyte, and $\mathrm{pH}$ of the medium strongly influence the adsorption efficiency of the membranes. Although the membranes are made of PS electrospun fibers, their maximum adsorption capacity (from breakthrough curves) for BSA was $270 \mathrm{mg} \cdot \mathrm{g}^{-1}$. This result is similar to the literature examples, which typically involve expensive and complicated synthesis processes. ${ }^{[18,53,54]}$ These membranes offer opportunities for improved protein adsorption, particularly when surface modification with Au NPs is employed. $\mathrm{Au}-\mathrm{NP}$ modification significantly increased the BSA adsorption from 66 to $111 \mathrm{mg} \cdot \mathrm{g}^{-1}$. The concentration of DNA with respect to that of BSA increased fourfold in the eluted solution. The electrospun membranes hold great potential for the fast and effective separation of DNA from a simulative serum. They also have the potential to be developed for the separation of DNA biomarkers for diagnosis. 


\section{Supporting Information}

Supporting Information is available from the Wiley Online Library or from the author.

Acknowledgements: The authors thank the Centre for Materials Research, Environmental Research Center and Biotechnology, and Bioengineering Research and Application Centre of IZTECH. MMD acknowledges the 2014 FABED Eser Tümen Outstanding Young Scientist Award.

Received: March 11, 2016; Revised: April 5, 2016; Published online: May 4, 2016; DOI: 10.1002/mame.201600127

Keywords: adsorption; bioseparation; BSA; DNA biomarkers; electrospinning

[1] M. V. Alok Mishra, Cancers 2010, 2, 190.

[2] A. Ziegler, A. Koch, K. Krockenberger, A. Grosshennig, Hum. Genet. 2012, 131, 1627.

[3] M. G. Schrauder, R. Strick, R. Schulz-Wendtland, P. L. Strissel, L. Kahmann, C. R. Loehberg, M. P. Lux, S. M. Jud, A. Hartmann, A. Hein, C. M. Bayer, M. R. Bani, S. Richter, B. R. Adamietz, E. Wenkel, C. Rauh, M. W. Beckmann, P. A. Fasching, Plos One 2012, 7, e29770.

[4] B. S. S. A. Leon, D. M. Sklaroff, M. J. Yaros, Cancer Res. 1977, $37,646$.

[5] V. Swarup, M. R. Rajeswari, FEBS Lett. 2007, 581, 795.

[6] U. H. Yildiz, P. Alagappan, B. Liedberg, Anal. Chem. 2013, 85, 820.

[7] A. Palaniappan, J. A. Cheema, D. Rajwar, G. Ammanath, L. Xiaohu, L. Seng Koon, W. Yi, U. H. Yildiz, B. Liedberg, Analyst 2015, 140, 7912.

[8] Roche Life Science, www.lifescience.roche.com/shop/home, accessed: March, 2015.

[9] Z. Ma, K. Masaya, S. Ramakrishna, J. Membr. Sci. 2006, 282, 237.

[10] Z. M. Huang, Y. Z. Zhang, M. Kotaki, S. Ramakrishna, Compos. Sci. Technol. 2003, 63, 2223.

[11] N. Bhardwaj, S. C. Kundu, Biotechnol. Adv. 2010, 28, 325.

[12] P. Lu, B. Ding, Recent Patents Nanotechnol. 2008, 2, 169.

[13] M. M. Demir, M. A. Gulgun, Y. Z. Menceloglu, B. Erman, S. S. Abramchuk, E. E. Makhaeva, A. R. Khokhlov, V. G. Matveeva, M. G. Sulman, Macromolecules 2004, 37, 1787.

[14] N. Horzum, T. Shahwan, O. Parlak, M. M. Demir, Chem. Eng. J. 2012, 213, 41.

[15] Z. W. Ma, M. Kotaki, S. Ramakrishna, J. Membr. Sci. 2005, 265,115

[16] Z. Ma, S. Ramakrishna, J. Membr. Sci. 2008, 319, 23.

[17] H. Esfahani, M. P. Prabhakaran, E. Salahi, A. Tayebifard, M. Keyanpour-Rad, M. R. Rahimipour, S. Ramakrishna, J. Colloid Interface Sci. 2015, 443, 143.

[18] T. Lan, Z.-q. Shao, M.-j. Gu, Z.-w. Zhou, Y.-l. Wang, W.-j. Wang, F.-j. Wang, J.-q. Wang, J. Membr. Sci. 2015, 489, 204.

[19] G. Fan, J. Ge, H.-Y. Kim, B. Ding, S. S. Al-Deyab, M. El-Newehy, J. Yu, RSC Adv. 2015, 5, 64318.

[20] A. Lancuski, F. Bossard, S. Fort, Biomacromolecules 2013, 14, 1877.

[21] S. R. Dods, O. Hardick, B. Stevens, D. G. Bracewell, J. Chromatogr. A 2015, 1376, 74.
[22] H.-T. Chiu, J.-M. Lin, T.-H. Cheng, S.-Y. Chou, C.-C. Huang, J. Appl. Polym. Sci. 2012, 125, E616.

[23] T. Zhu, D. Xu, Y. Wu, J. Li, M. Zhou, T. Tian, Y. Jiang, F. Li, G. Li, J. Mater. Chem. B 2013, 1, 6449.

[24] M. F. Leong, K. S. Chian, P. S. Mhaisalkar, W. F. Ong, B. D. Ratner, J. Biomed. Mater. Res. A 2009, 89A, 1040.

[25] M. M. Demir, Express Polym. Lett. 2010, 4, 2.

[26] http://imagej.net/Welcome.

[27] Z. O. Uygun, M. K. Sezginturk, Anal. Chim. Acta 2011, 706, 343.

[28] M. M. Demir, N. Horzum, A. Tasdemirci, K. Turan, M. Guden, ACS Appl. Mater. Interfaces 2014, 6, 21901.

[29] C.-L. Pai, M. C. Boyce, G. C. Rutledge, Macromolecules 2009 , 42, 2102.

[30] V. Jacobs, R. D. Anandjiwala, M. Maaza, J. Appl. Polym. Sci. 2010, 115, 3130

[31] P. k. Baumgart, J. Colloid Interface Sci. 1971, 36, 71.

[32] M. M. Demir, I. Yilgor, E. Yilgor, B. Erman, Polymer 2002, 43, 3303.

[33] N. Horzum, R. Munoz-Espi, G. Glasser, M. M. Demir, K. Landfester, D. Crespy, ACS Appl. Mater. Interfaces 2012, 4, 6338.

[34] S. Kaur, S. Sundarrajan, D. Rana, T. Matsuura, S. Ramakrishna, J. Membr. Sci. 2012, 392, 101.

[35] Z. L. Gu, Z. X. Yang, Y. Chong, C. C. Ge, J. K. Weber, D. R. Bell, R. H. Zhou, Sci. Rep. 2015, 5, 9.

[36] S. R. Saptarshi, A. Duschl, A. L. Lopata, J. Nanobiotechnol. 2013, 11, 26

[37] D.-X. Hao, Y.-D. Huang, K. Wang, Y.-P. Wei, W.-O. Zhou, J. Li, G.-H. Ma, Z.-G. Su, J. Mater. Chem. B 2014, 2, 1770.

[38] S. H. Lee, E. Ruckenstein, J. Colloid Interface Sci. 1988, 125, 365.

[39] C. Dietschweiler, Protein adsorption at solid surfaces, Term paper, Swiss Federal Institute of Technology, Zürich, 2008.

[40] M. D. Sindkhedkar, H. R. Mulla, A. Cammers-Goodwin, J. Am. Chem. Soc. 2000, 122, 9271.

[41] R. Kun, M. Szekeres, I. Dekany, J. Therm. Anal. Calorim. 2009, 96, 1009.

[42] Y. L. H. Möhwald, Protein Architecture: Interfacing Molecular Assemblies and Immobilization Biotechnology, 1st ed., CRC Press, New York, 1999.

[43] K. B. Cederquist, C. D. Keating, ACS Nano 2009, 3, 256.

[44] S. J. Hurst, A. K. R. Lytton-Jean, C. A. Mirkin, Anal. Chem. 2006, 78, 8313.

[45] C.-L. Pai, M. C. Boyce, G. C. Rutledge, Polymer 2011, 52, 6126.

[46] D. Cabuzu, A. Cirja, R. Puiu, A. M. Grumezescu, Curr. Top. Med. Chem. 2015, 15, 1605.

[47] R. Fu, C. Wang, J. O. Zhuang, W. S. Yang, Colloids Surf. A 2014, $444,326$.

[48] N. Nimi, W. Paul, C. P. Sharma, Gold Bull. 2011, 44, 15.

[49] S. H. D. P. Lacerda, J. J. Park, C. Meuse, D. Pristinski, M. L. Becker, A. Karim, J. F. Douglas, ACS Nano 2010, 4, 365.

[50] R. Zhong, Y. Liu, P. Zhang, J. Liu, G. Zhao, F. Zhang, ACS Appl. Mater. Interfaces 2014, 6, 19465.

[51] M. Gerstein, A. M. Lesk, C. Chothia, Biochemistry 1994, 33, 6739.

[52] W. Norde, Biopolymers at Interfaces, CRC Press, New York, 1998.

[53] E. B. Altintas, A. Denizli, J. Chromatogr. B 2006, 832, 216.

[54] J. Gu, Z. Lei, O. Yao, J. Membr. Sci. 2007, 287, 271.

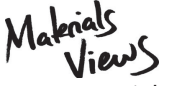

www.MaterialsViews.com 